\title{
Continuous Monitoring of Information \\ on Anode Current Distribution as Means \\ of Improving the Process of Controlling \\ and Forecasting Process Disturbances
}

\author{
Iliya I. Puzanov*a, \\ Andrey V. Zavadyak ${ }^{a}$, Vladimir A. Klykov ${ }^{a}$, \\ Anton V. Makeev ${ }^{\mathrm{a}}$ and Vadim N. Plotnikov ${ }^{\mathrm{b}}$ \\ ${ }^{a}\langle R U S A L E T C » L L C$ \\ 37/1 Pogranichnikov, Krasnoyarsk, 660111, Russia

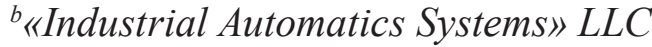 \\ 13660 let Oktyabrya, 660079, Russia
}

Received 10.02.2016, received in revised form 13.03.2016, accepted 29.06.2016

The aluminum reduction process control system in recent decades has given great opportunities for improving the collection and processing of signals that provide the basis for the adjustment of feeding, thermal balance and magnetohydrodynamic (MHD) stability. Despite considerable development, there is a growing need for control sensors that can detect and respond to emerging changes.

Since 2008, the cells operating in the RA-400 pilot area inside the Pilot Potroom at OJSC RUSAL Sayanogorsk have been using a system for continuous monitoring of information on anode current distribution. The system has been integrated in the 'CAAT-2' control system.

In the course of industrial tests, the monitoring system was continuously improved - in terms of information reliability, and equipment operability in aggressive environments and during pot tending \& maintenance operations.

The obtained information on anode current distribution allowed for developing algorithms to detect, at an early stage, variations in cell alumina feeding, including further alumina redistribution between feed points, and forecast and detect anode bottom problems ("spike").

Keywords: problem cell, current distribution, spike (point), pointed anode, anode grounding, ACD (Anode-Cathode Distance).

Citation: Puzanov I.I., Zavadyak A.V., Klykov V.A., Makeev A.V., Plotnikov V.N. Continuous monitoring of information on anode current distribution as means of improving the process of controlling and forecasting process disturbances, J. Sib. Fed. Univ. Eng. technol., 2016, 9(6), 788-801. DOI: 10.17516/1999-494X-2016-9-6-788-801.

(C) Siberian Federal University. All rights reserved

* Corresponding author E-mail address: Iliya.Puzanov@rusal.com 


\title{
Совершенствование процесса управления
}

\section{и прогнозирования технологических нарушений путем непрерывного мониторинга информации \\ о распределении тока по анодам}

\author{
И.И. Пузанова , А.В. Завадяка, \\ В.А. Клыков ${ }^{\mathrm{a}}$, А.В. Макеев ${ }^{\mathrm{a}}$, В.Н. Плотников ${ }^{6}$ \\ ${ }^{a} О О О$ «РУСАЛ ИТЦ» \\ Россия, 660111, Красноярск, Пограничников, 37/1 \\ ${ }^{6} О О О$ «Системы промышленной автоматики» \\ Россия, 660079, Красноярск, 60 лет Октября, 136
}

\begin{abstract}
За последние десятилетия система АСУТП электролиза достигла больших возможностей по улучшению сбора и обработки сигналов, которые обеспечивают основу для регулирования питания, теплового баланса и магнитогидродинамической (МГД) стабильности. Несмотря на значительное развитие, постоянно растут потребности в датчиках контроля, которые могут распознавать и реагировать на возникающие изменения.

C 2008 г. на электролизерах опытного участка PA-400, расположенного в опытнопромышленном корпусе электролиза ОАО «РУСАЛ Саяногорск», эксплуатируется система непрерывного мониторинга информащии о распределении тока по анодам, интегрированная в АСУТП СААТ-2.

На протяжении промышленных испытаний система мониторинга постоянно совершенствовалась в части достоверности информации, обеспечения работоспособности оборудования в условиях агрессивных сред, а также при выполнении технологических и ремонтных операций на электролизере.

Полученная информация о распределении тока по анодам позволила разработать алгоритмы, прогнозирующие на ранней стадии отклонения в питании глиноземом электролизера c последующим перераспределением по точкам автоматической подачи глинозема (АПГ), прогнозирование и распознавание технологических нарушений на подошве анодов («конуса»).
\end{abstract}

Ключевые слова: нарушение на ванне, токораспределение, «конус», неровность на аноде, подмыкание анода, междуполюсное расстояние (МПР).

\section{Введение}

Основная задача любой автоматизированной системы управления технологическим процессом - поддержание в заданных пределах наиболее важных параметров этого процесса.

На текущий момент в промышленных условиях непрерывно измеряемы лишь два параметра: ток серии и напряжение электролизера. Такие важные технологические параметры, как температура и химический состав электролита, уровни расплава, измеряются вручную и с недостаточной частотой, поэтому управляются по косвенным параметрам.

Расширение функциональности АСУТП и применение новых алгоритмов управления требуют значительного увеличения контролируемых параметров процесса электролиза алюминия. Актуальным направлением увеличения количества анализируемых данных является разработка системы измерения токораспределения по анодам электролизера. 
Особенную сложность при разработке автоматических систем, функционирующих на электролизерах, вносит агрессивная среда (наличие фторидов в атмосфере, высокие температуры, различные технологические и ремонтные операции с использованием механизмов) [1].

\section{Система измерения тока по анодам}

Для измерения значения тока в любом проводнике возможно применение различных способов, каждый из них имеет свои преимущества и недостатки. Измерение токораспределения по анодам электролизера РА-400 накладывает значительные ограничения на применение тех или иных способов, а именно: большие абсолютные значения тока анода, высокая температура и агрессивность среды в месте измерения.

Наиболее приемлемый метод, который возможно использовать в данных условиях, это дифференциальное измерение падения напряжения на проводнике (анодной ошиновке электролизера) [2]. Такой недостаток, как точность, которую возможно оценить как 5-10\%-ю, представляется достаточной для анализа токораспределения. Еще один недостаток в виде чувствительности к изменению температуры проводника, а соответственно и к удельному сопротивлению, компенсируется датчиками температуры анодной шины. Современная элементная база промышленной электроники позволяет с достаточной точностью измерять низкое выходное напряжение датчика в диапазоне 0-2000 мкВ. Измерительную базу (расстояние между точками измерения падения) необходимо выбрать минимально возможной. Это связано в первую очередь с тем, что анодная шина соприкасается с различными конструктивными элементами (замок анодной штанги, подводящие шины), что, в свою очередь, проявляется как изменение сечения анодной шины, которое во многих случаях не имеет смысла измерять заранее и учитывать, так как эта величина может изменяться во времени, например после замены анода.

Для проведения достаточно точных измерений следует необходимость измерения температуры на анодной шине электролизера, поскольку при изменении температуры анодной ошиновки от 65 до $110{ }^{\circ} \mathrm{C}$ сопротивление анодной ошиновки меняется на $18 \%$, что недопустимо. Это обуславливает необходимость установки датчиков температуры по краям каждой четверти анодной шины, а температуру в других точках интерполировать по значениям температуры на краях шины, считая, что температура по длине шины возрастает (уменьшается) по линейному закону. Данное упрощение позволяет в значительной степени компенсировать влияние температуры на измерение токораспределения.

Датчик измерения падения напряжения на анодной шине представляет собой два электрода, установленных на анодной шине на расстоянии 50 мм друг от друга. Место расположения датчика (рис. 1) выбирают максимально близко к креплению штанги анода на шине, при этом на протяжении расстояния между анодами шина должна иметь равное сечение.

\section{Текущее управление распределением тока}

по анодам на PA-400

По мере увеличения мощности электролизеров увеличивается и количество устанавливаемых анодов. Как следствие, при вовлечении в производство анодов низкого качества возникает высокая погрешность в обнаружении проблемного анода, а при работе на низком междуполюсном расстоянии (МПР) потребность в оперативном обнаружении проблемных анодов

$$
-790-
$$




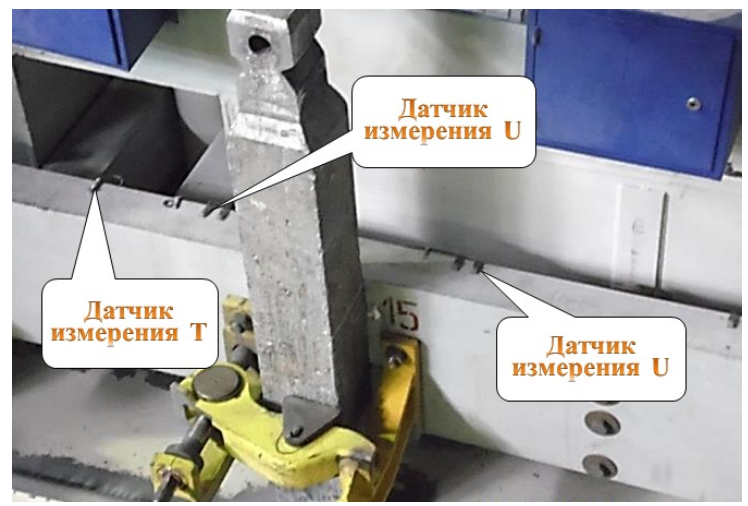

Рис. 1. Установка датчиков на анодной шине

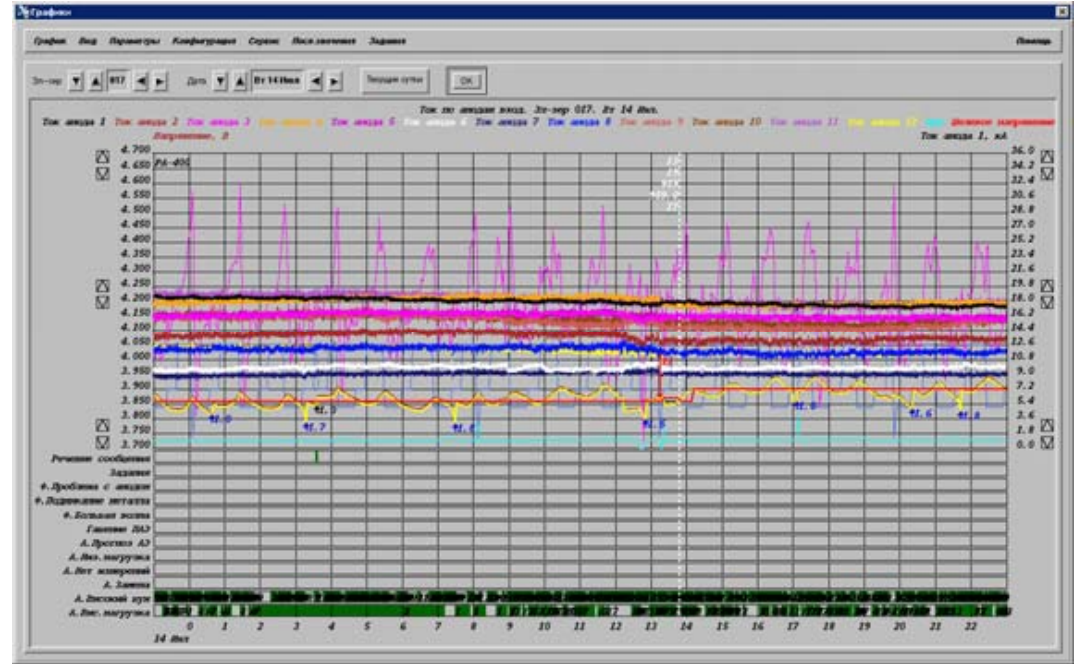

Рис. 2. Отображение значений тока анодов в системе визуализации «ЭлВИС»

возрастает на порядок. Поэтому оперативная и точная информация о распределении тока по анодам необходима для достижения высокой эффективности работы электролизера, а также для его стабильности.

В настоящее время на верхнем уровне АСУТП в системе визуализации «ЭлВИС» информация о токах отображается на графике (рис. 2), что позволяет технологу в режиме реального времени отслеживать не только проблемные электролизеры, но и локализацию самого расстройства на ванне.

За период эксплуатации системы нами было использовано множество способов обработки поступающих значений токов (усреднение, фильтрация), но наиболее приемлемым оказался метод фильтрации с подборкой опытным путем коэффициентов сглаживания.

Обработанные данным способом значения использовались для написания алгоритмов, которые в период опытной эксплуатации подтвердили расчетные данные и в настоящее время полноценно применяются в АСУТП.

$$
-791-
$$




\section{Прогнозирование и распознавание отклонений в питании глиноземом}

На основе данных индивидуального распределения токов по анодам нами был разработан ряд алгоритмов по выявлению нарушений в работе АПГ. В отличие от классического способа измерения концентрации глинозема в электролите по «приращению» напряжения, который не учитывает непостоянство концентрации по всему расплаву, система токораспределения дает возможность определять изменение концентрации глинозема по всем участкам ванны. Это позволяет повысить качество управления системой АПГ за счет перераспределения питания на зоны с пониженной концентрацией глинозема, выявлять нарушения в работе системы АПГ («непробои» и проч.) и на ранней стадии делать прогноз АЭ.

Разработка алгоритмов проводилась на ежедневном анализе работы электролизера и сопоставлении выявленных нарушений.

Ниже приведены примеры выявлений отклонений, отработка гипотез, разработка и подтверждение принятых решений.

\section{Прогнозирование АЭ}

Анализируя динамики распределения тока по анодам, выявили, что перед возникновением АЭ на одних анодах ток начинает расти, на других - снижаться.

Это обусловлено тем, что возникновение АЭ начинается с пассивации одного или нескольких анодов, а затем распространяется на другие области, следовательно, одни аноды изолируются, другие же, наоборот, берут повышенную нагрузку [3].

На рис. 3 представлена динамика фильтрованного тока по анодам и режим АПГ до и после возникновения АЭ. Можно видеть, что примерно за 35 мин до возникновения АЭ началось перераспределение нагрузки на анодах. На одних ток проходил с меньшей дисперсией, на других - с большей. Данный факт позволил нам на ранней стадии прогнозировать АЭ с последующим внедрением алгоритмов распределения питания глинозема по точкам в зависимости от

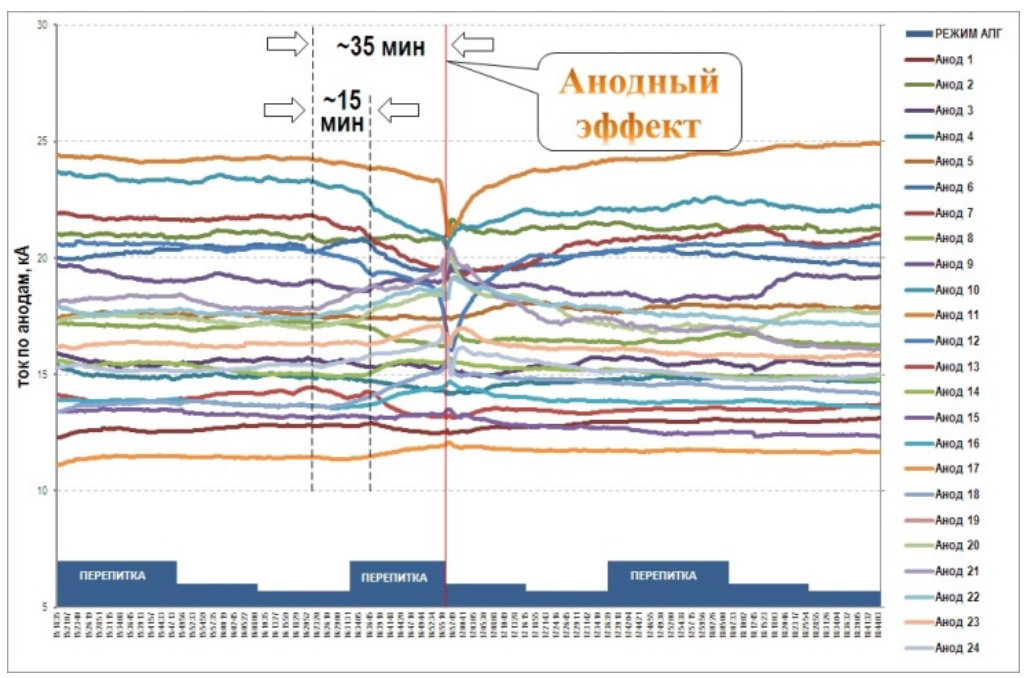

Рис. 3. Динамика тока по анодам и режим АПГ до АЭ 
причин возникновения АЭ (неисправность механизмов АПГ, «непробои» корки, неравномерность концентрации глинозема в расплаве и т.д.).

\section{Перераспределение глинозема по точкам АПГ}

Анализируя причину АЭ на опытном электролизере, выявили, что АЭ возник из режима «голодания» установленного после замены анода (когда на электролизере максимальное целевое напряжение).

При визуальном осмотре и оценке работы АПГ значительных отклонений не обнаружено.

Однако, детально анализируя график «напряжения» (рис. 4), выявили, что после выливки металла наблюдались значительные приросты «приращения напряжения».

На основе полученных данных был построен график индивидуального распределения тока по анодам (рис. 5), который показал, что при смене режимов АПГ на одних анодах ток не меняется, на других анодах наблюдалось изменение распределения тока по-разному:

- при переходе из режима АПГ «недопитки» в «перепитку» ток возрастает и наоборот;

- при переходе из режима АПГ «недопитки» в «перепитку» ток снижается и наоборот.

На рис. 5 видно, что при переходе режима АПГ из «недопитки» в «перепитку» на анодах № 7, 15 ток снижается, а на анодах № 6, 19 возрастает.

На рис. 6 схематично представлено расположение анодов и точек АПГ в проекции катодного кожуха PA-400.

Рисунок 6 демонстрирует, что на анодах № 7 (10 сут после установки) и 15 (13 сут после установки) происходит пассивация анода газовым слоем и аноды перестают брать нагрузку, как следствие, происходит перераспределение тока и соседние аноды № 16 (15 сут после установки), № 19 (23 сут после установки) начинают брать бо́льшую нагрузку.

Более детальный анализ работы АПГ (замер дозы, визуальная проверка) показал, что на дозаторах № 2 и 4 наблюдалась пониженная доза из-за проблем, связанных с закачкой АПГ с помощью ЦРГ.

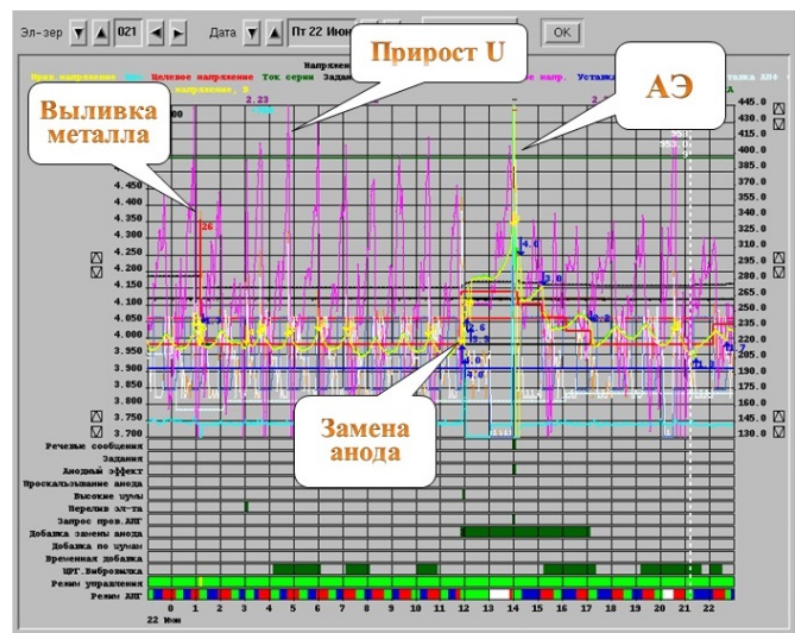

Рис. 4. График «напряжения» в системе визуализации «ЭлВИС»

$$
-793-
$$




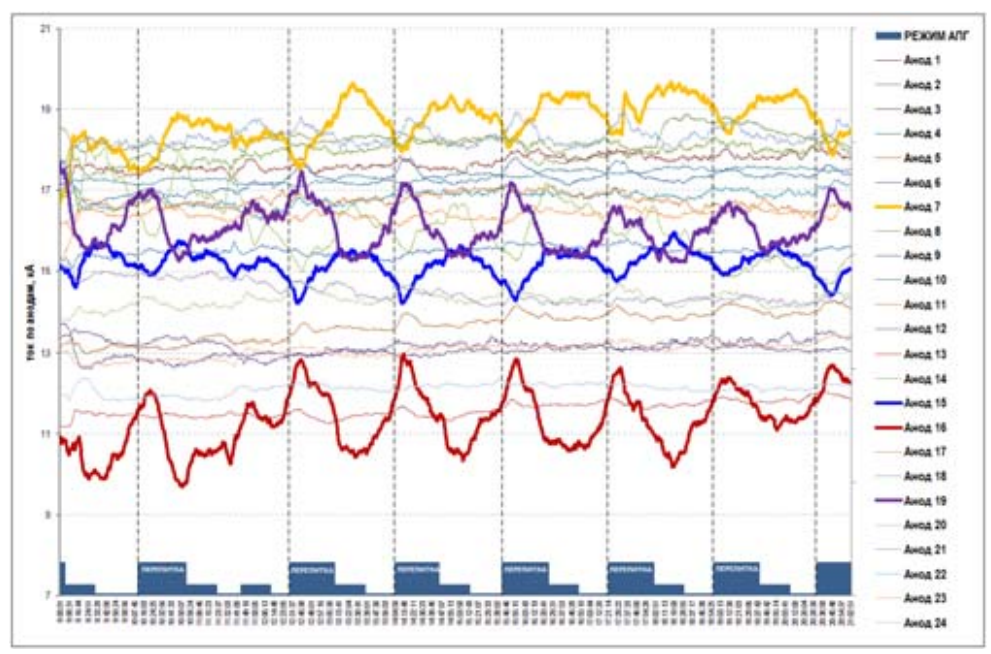

Рис. 5. Динамика тока по анодам и режим АПГ

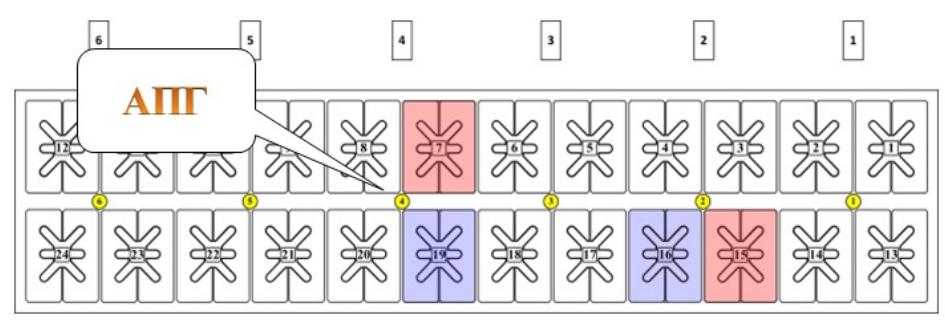

Рис. 6. Расположение анодов и точек АПГ в проекции катодного кожуха РА-400

Данный факт свидетельствует о том, что на анодах, где при переходе режима АПГ из «недопитки» в «перепитку» ток снижается, происходит изоляция подошвы анода газовым пузырем, что может являться как зоной с пониженной концентрацией глинозема, так и застойной зоной со слабопротекающими процессами.

Таким образом, для исключения пассивации анодов № 7, 15 необходимо усилить подачу глинозема в режиме «перепитка» через точки питания № 2, 4. На основе полученных данных был разработан следующий алгоритм:

1. Выполняется оценка абсолютного приращения фильтрованного тока по анодам в режиме «недопитка».

2. Если абсолютный прирост снижается на ближайшей к аноду точке АПГ, на время режима «перепитка» увеличивается подача глинозема.

Для подтверждения адекватности разработанного алгоритма проведен ряд экспериментов, имитирующих различную поломку системы АПГ электролизера РА-400 (поломка от одного до четырех пробойников, поломка пробойника в различных зонах электролизера).

Проведенные эксперименты показали, что разработанный алгоритм интерпретирован неверно, так как в большинстве случаев причиной пассивации анодов является отсутствие подачи глинозема из-за поломки механизмов АПГ или «непробоя» корки, когда глинозем не по- 
ступает в расплав, а образует кучи («кроты») над ним, вследствие чего питание от проблемной зоны необходимо перераспределить на остальные точки АПГ. Доработанный алгоритм дал положительные результаты.

\section{Нестабильность тока - «шум»}

В АСУТП СААТ-2 под «шумом» понимается величина амплитуды колебаний приведенного напряжения электролизера за определенный период. При нормальной работе электролизера колебания напряжения обусловлены сходом газовых пузырей с «подошвы» анода и имеют незначительную амплитуду (5-10 мВ при использовании анодов с пазами, 10-15 мВ при использовании анодов без пазов) и частоту колебаний (0,5-2,0 Гц).

Изменение характера и величины «шума» является интегральным индикатором наличия технологических нарушений на электролизере.

Подход по оценке величины «шума» тока по аноду был применен при прогнозировании и распознавание технологических нарушений на подошве анодов.

\section{Прогнозирование и распознавание технологических нарушений}

\section{на подошве анодов}

Одним из основных определяющих факторов достижения высоких ТЭП на серии электролизеров является минимальное количество электролизеров с технологическими нарушениями. Максимально быстро установить и устранить первопричину технологического расстройства в случае его возникновения, разработать и осуществлять корректирующие мероприятия по предупреждению повторного возникновения - задача персонала, управляющего процессом. Для минимизации количества проблемных электролизеров необходимо соблюдение следующих условий:

- качественное выполнение технологических операций;

- своевременная диагностика технологических проблем на ранней стадии;

- минимальное время реакции на технологические нарушения.

Ключевым технологическим нарушением, значительно снижающим выход по току, является нарушение на «подошве» анодов («конуса»). Под данным нарушением понимается образование на рабочей поверхности анодов локальных участков, на которых МПР значительно ниже.

Данное нарушение чрезвычайно опасно, так как приводит к стремительной потере выхода по току на электролизере за счет следующих причин:

- интенсивное протекание обратной реакции, вызванное локальным разогревом расплава в районе нарушения за счет протекания большего тока вследствие уменьшенного электрического сопротивления (меньшее МПР);

- локальное шунтирование электролизера при контакте нарушения на аноде с поверхностью металла [4].

Длительные наблюдения на опытном участке РА-400 показали, что один выявленный «конус» на электролизер приводит к снижению выхода по току примерно на 1,5 \%.

По своему внешнему виду на ОАО «РУСАЛ Саяногорск» нарушения на подошве анодов условно разделены на три типа:

$$
-795-
$$


- «типичный конус» - образование на подошве анодов правильной цилиндрической или конической формы у основания;

- «отставание» - выступы на рабочей поверхности анода прямоугольной формы или неровность, занимающая до 50-60 \% площади анода;

- «nерекал» - нарушение на подошве анода неправильной формы (шар, гриб и т.п.), образованное непосредственно у любой грани анодного блока.

«Конусы» на ОАО «РУСАЛ Саяногорск» диагностируются по следующим симптомам:

- высокий / низкий «шум»;

- повышенная нагрузка на аноде;

- низкое потребление глинозема;

- высокий перегрев и температура;

- низкий уровень электролита;

- огни желтого цвета;

- покраснение ниппелей анододержателей.

Однако данные симптомы возникают уже при наличии «конуса» на аноде, а применяемые методы обнаружения достаточно неэффективны.

Одной из основных задач, стоящих перед специалистами ИТЦ, была разработка технологии, позволяющая прогнозировать и распознавать технологические нарушения на подошве анодов посредством мониторинга информации о распределении тока по анодам. При вовлечении в производство сырья хорошего качества (преимущественно анодных блоков) при высоком уровне ведения технологии ( $¥>94,5 \%, \mathrm{~W}<13250$ кВт×ч/т) образование «конусов» - достаточно редкое. Однако на протяжении последних лет нам удалось накопить достаточно информации, позволяющей прогнозировать и распознавать «конусы».

В настоящее время разработаны алгоритмы распознания нарушений в следующих случаях:

1. Образование «типичного конуса» в первой половине цикла установки анода, вызванного:

- низким качеством анодного блока (требует проведения дополнительных исследований);

- некачественным выполнением технологической операции по замене анода.

2. Образование «типичного конуса»/«перекала» во второй половине цикла, связанного с подмыканием на пену.

Обнаружение «конуса»

в первой половине цикла установки анода

На рис. 7 представлен характерный пример того, как берет нагрузку анод с «конусом» в течение десяти суток после его установки на электролизер и как изменяется шум тока по аноду, а также отображена фотография данного анода с нарушением, идентифицированным как «типичный конус» (образование правильной конической формы у основания диаметром 8 см).

Представленная на рис. 7 динамика наблюдалась практически на всех анодах, на которых были обнаружены нарушения примерно на 8-12 сут после установки анода. Для всех динамик наблюдались одинаковые закономерности, а именно:

$$
\text { - } 796 \text { - }
$$




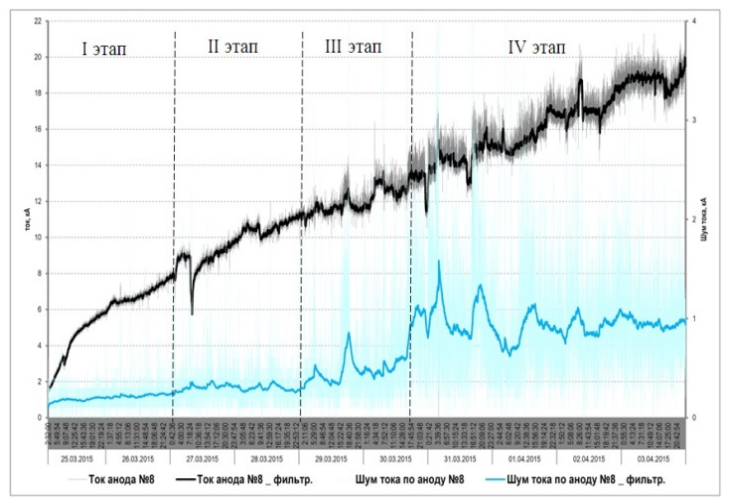

a

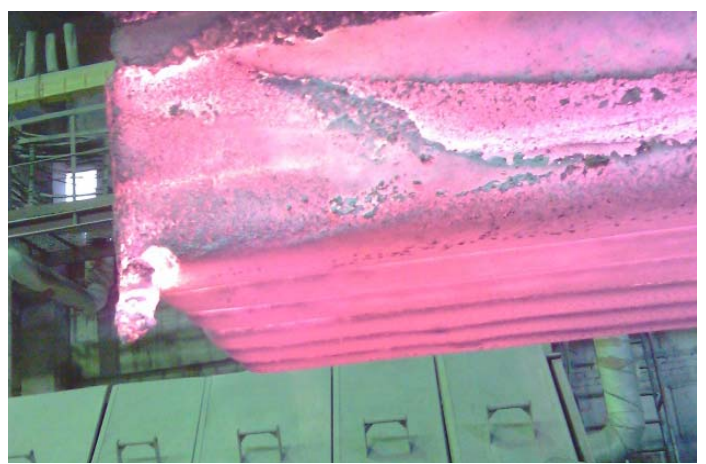

6

Рис. 7. Динамика тока по аноду с наличием «конуса» в течение 10 сут после установки: а - диаграмма динамики нагрузки и шума на аноде; б - анодный блок с «конусом»

1. На протяжении анализируемого жизненного цикла анод берет аномально низкую нагрузку (ниже номинального значения), при этом ток растет по линейной зависимости.

2. Примерно на 6-е сутки после установки анода начинает наблюдаться рост шума тока по аноду.

После анализа и оценки значений была выдвинута следующая гипотеза (или механизм) образования нарушения на подошве анода, разбитая на четыре этапа.

Этап № 1. После установки анода первые двое суток затвердевшее сырье на аноде постепенно расплавляется, анод нагревается, начинает брать нагрузку, и его подошва выходит на «горизонт анодного массива», однако нагрузка значительно ниже номинального значения.

Этап № 2. После того как подошва анода вышла на «горизонт анодного массива», на локальных участках начинают образовываться «отставания». О данном факте свидетельствует рост шума тока по аноду. Данный этап мы интерпретировали как начало формирования «конуса» и нахождение его в расплаве

Этап № 3. На данном этапе «конус» сформировался, его высота достигает МПР. Как следствие, идет подмыкание, о чем свидетельствует значительный рост шума тока по аноду.

Этап № 4. На данном этапе «конус» полностью замкнул на металл, это видно из остановки роста шума тока по аноду, и «конус» начинает расти, о чем свидетельствует линейное повышение тока по аноду.

Для сравнения на рис. 8 изображено, как берет нагрузку нормальный анод и анод, у которого на подошве образуется «конус». Мы видим, что на рядовом аноде примерно на третьи сутки после установки нагрузка достигает номинального значения и рост прекращается, а на аноде с «конусом» нагрузка постоянно растет.

В данном случае если применять типичный подход по управлению нагрузкой на анодах, то «конус» будет обнаружен только после превышения нагрузки номинального значения, а именно на 10-12-е сутки после установки. Применение разработанного подхода по обнаружению «конусов» по динамике тока и шума тока позволяет выявить нарушение на 5-7-е сутки после его установки. 


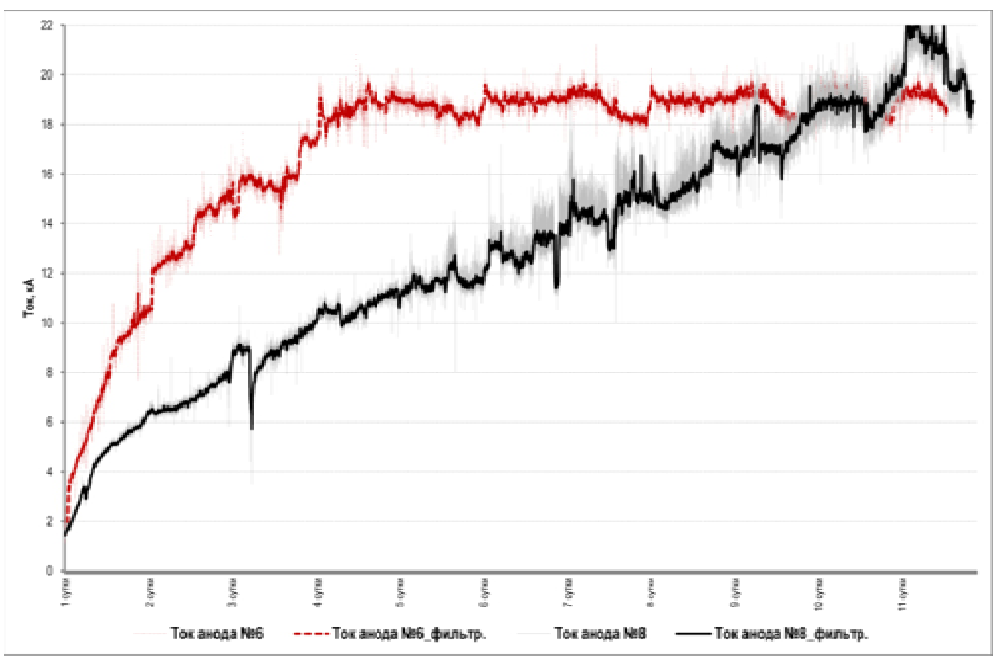

Рис. 8. Динамика тока по анодам с конусом и без него в течение 11 суток после установки

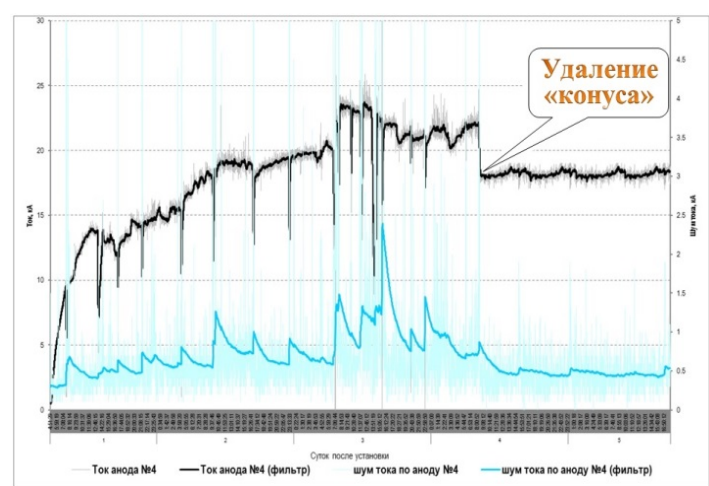

a

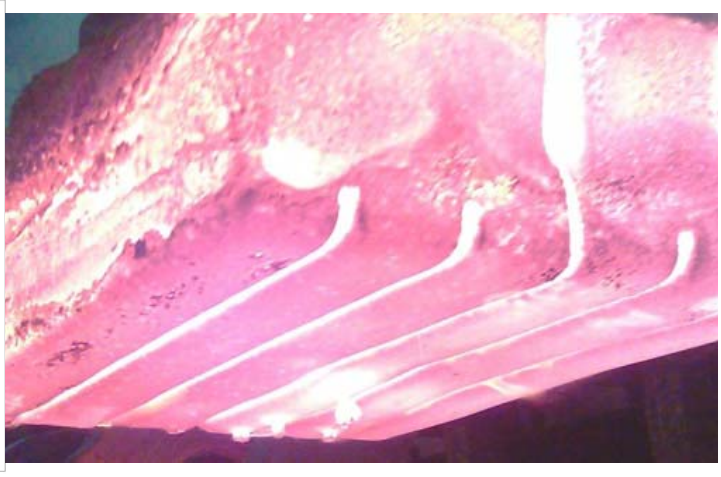

6

Рис. 9. Динамика тока по аноду при некачественно выполненной операции по замене анода в течение 5 суток после установки: а - диаграмма динамики нагрузки и шума на аноде; б - анодный блок с «конусом»

Вторая причина образования «конусов» связана с нарушением регламента выполнения технологических операций или с образованием угольной пены.

\section{Обнаружение «конуса»}

из-за некачественно выполненной операции по замене анода

На рис. 9 представлен характерный пример того, как берет нагрузку анод и как меняется шум тока по аноду после некачественно выполненной операции по замене анода с последующим обнаружением «конуса», и фотография данного анодного бока с нарушением на подошве.

Все анализируемые динамики имели одинаковые закономерности:

1. На третьи сутки после установки нагрузка достигает номинального значения.

$$
\text { - } 798 \text { - }
$$


2. Сразу же после установки анода наблюдаются высокий шум тока по аноду и подмыкание анода на металл.

Обнаружение «конуса»во второй половине цикла,

связанного с подмыканием на пену.

На рис. 10 изображено, как берет нагрузку анод и как меняется шум тока по аноду с обнаружением «конуса» во второй половине жизненного цикла, и фотография данного анодного бока с нарушением на подошве. Такая динамика наблюдалась практически на всех анодах, на которых были обнаружены нарушения примерно после 15-х суток установки анода.

Для всех динамик были характерны одинаковые закономерности:

1. На третьи сутки после установки нагрузка достигает номинального значения.

2. Примерно на третьи сутки после установки анода начинает наблюдаться рост шума тока по аноду. Отличительная особенность от вышеописанного случая - второй этап (когда начинает расти «конус») длится дольше (более 3 сут). По-видимому, в данном случае происходит накопление пены под анодом.

3. На третьем этапе «конус» сформировался и нагрузка на аноде начинает возрастать линейно.

4. На четвертом этапе «конус» достигает таких размеров, что происходит шунтирование анода и нагрузка на аноде начинает снижаться.

\section{Заключение}

Использование системы мониторинга индивидуального распределения тока по анодам является наиболее перспективным направлением как расширения функциональности АСУТП, так и совершенствования процесса управления технологией электролиза алюминия.

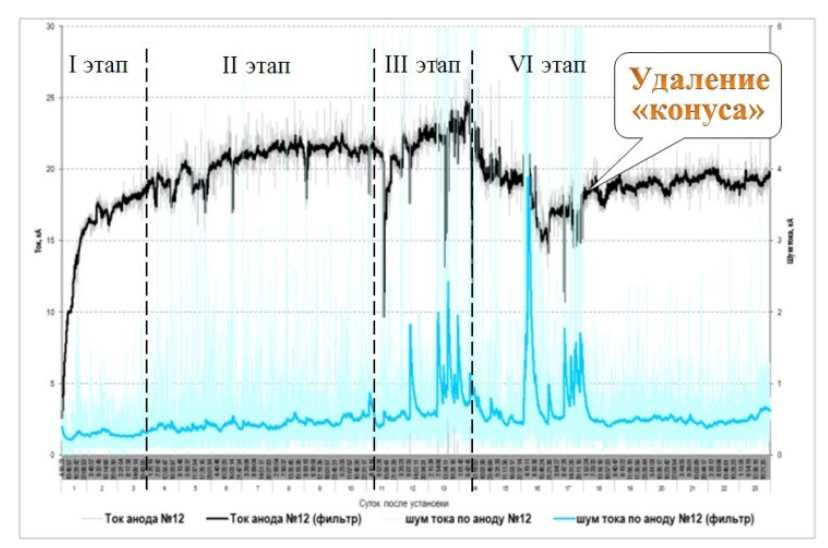

a

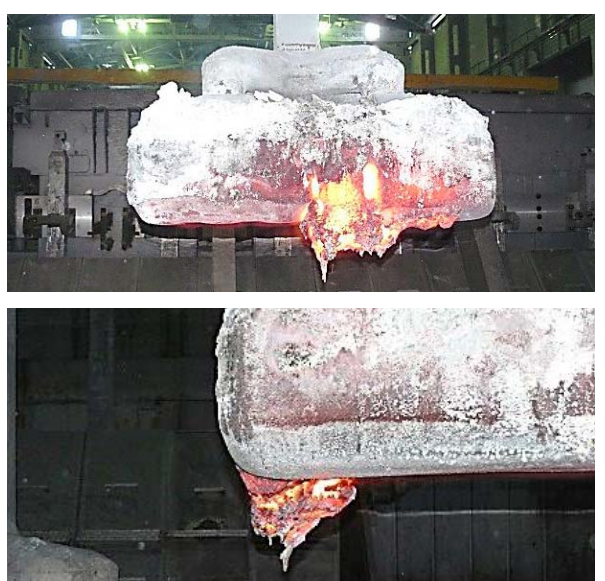

б

Рис. 10. Динамика тока по аноду в течение 23 суток после установки: а - диаграмма динамики нагрузки и шума на аноде; б - анодный блок с «конусом» 

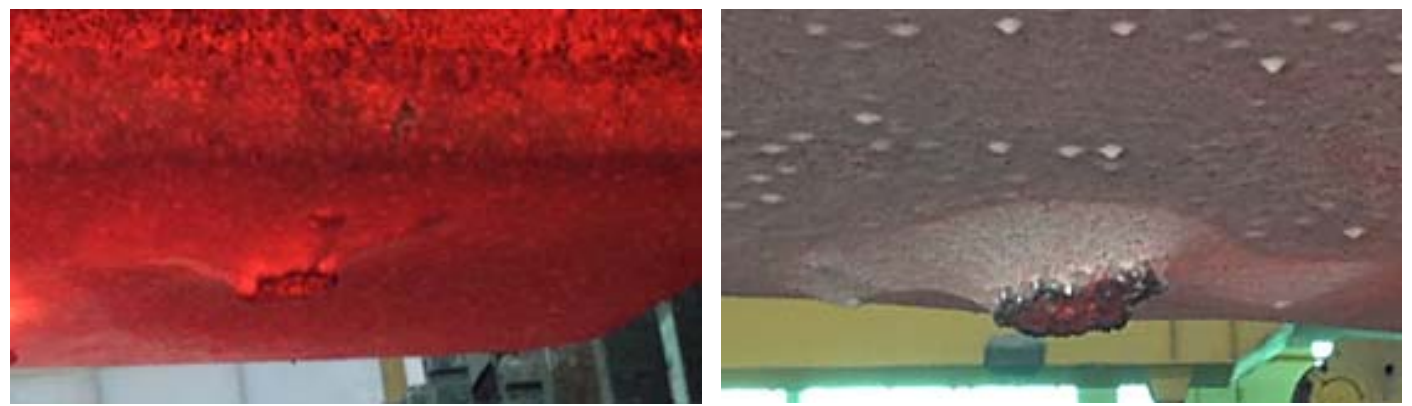

Рис. 11. Начало зарождения «конуса»

За период опытной эксплуатации данной системы нами было получено огромное количество информации, обработка которой (фильтрация, усреднение и т.д.) позволила установить алгоритмы управления и прогнозирования технологических нарушений.

В частности, были разработаны:

- алгоритм, позволяющий прогнозировать АЭ на ранней стадии;

- алгоритмы диагностики нарушений управления концентрацией глинозема с последующим перераспределением питания по точкам АПГ;

- алгоритмы диагностики и прогнозирования нарушений на аноде («конусов»), связанных как с нарушением регламента выполнения технологических операций, так и непосредственно с качеством самих анодных блоков.

Проведение ряда экспериментов и статистическая оценка полученных данных позволяет говорить о результатах, которые уже дали положительный эффект. В настоящее время разработанные алгоритмы полноценно используются в действующей АСУТП, а их внедрение позволило на порядок повысить качество управления процессом электролиза алюминия.

Тем не менее остается актуальным вопрос механизма образования конусов. В ходе проведенных исследований была выдвинута гипотеза, которая требует проведения дополнительных исследований и подтверждений:

1. За счет флуктуаций в аноде (неравномерностей) возникают большие локальные токи, как следствие - большое сопротивление анода и низкая нагрузка на аноде.

2. На поверхности анода за счет локальной высокой плотности возникают большие перенапряжения ( 0,7 В по Вэлчу), приводящие к разряду ионов фтора (CxFy), и поверхность пассивируется.

3. Далее в районе пассивированной поверхности ток перестает идти и перераспределяется по подошве анода (рис. 11).

4. На пассивированной поверхности анода начинает образовываться конус.

\section{Список литературы}

[1] Кенири Дж., Шайдулин Е.Р. Анализ анодного токораспределения - оптимизация управления электролизером. Алюминий Сибири - 2007: Материалы XIII Международной конференции. Красноярск: НТЦ «Легкие металлы», 2007, 4-13. [Keniry J., Shaydulin E.P. Anode signal

$$
-800-
$$


analysis - the next generation in reduction cell control. Aluminium of Siberia-2007: Materials of the XIII International Conference, Krasnoyarsk: STC «Light Metals», 2007, 4-13 (in Russian)]

[2] Вабищевич П.Н., Гусев А.В., Шайдулин Е.Р. Способ автоматического контроля технологического состояния алюминиевого электролизера: пат. 2307881 Рос. Федерация: МПК С $25 \mathrm{C} 3 / 20$; заявитель и патентообладатель ООО «Русская инжиниринговая компания». № 2005140166/02; заявл. 22.12.2005; опубл. 10.10.2007, Бюл. № 28. [Vabishevich P.N., Gusev A.V., Shaydulin E.P. Aluminum cell technical state automatic control method, RU 2307881, 2005, 8 (in Russian)]

[3] Ножко С.И. Питерцев Н.Н. Выход по току на алюминиевых электролизерах. Цветные металль - 2010: Сборник докладов второго международного конгресса, Красноярск, 2010, 478482. [Nozhko S.I., Pitertsev N.N. Current Efficiency of Aluminium Electrolysis Cells. Non-Ferrous Metals - 2010: Materials of the Second International Congress «Non-Ferrous Metals», 2010, 478-482 (in Russian)] 